\title{
Immunization Coverage and Associated Factors Among Children in Bila Town, West Wellega Zone, Oromia Regional State, Western Ethiopia
}

\author{
Takele Tiki $^{1 *}$, Teferra Likassa ${ }^{2}$, Dawit Endalew ${ }^{3}$ and Ayano Tolessa ${ }^{4}$ \\ ${ }^{1}$ Ambo University College of Medicine and Health Science Department of Psychiatry Nursing Ambo, Ethiopia \\ ${ }^{2}$ Ambo University College of Medicine and Health ScienceDdepartment of Nursing Ambo, Ethiopia \\ ${ }^{3}$ West Wellega Zone, Bila Town Health Office Unit of Maternity and Child Health, Bila Town, Western Ethiopia \\ ${ }^{4}$ Ambo University College of Medicine and Health Science Department of Medicine Ambo, Ethiopia \\ *Corresponding Author: Takele Tiki, Ambo University College of Medicine and Health Science Department of Psychiatry Nursing Ambo, \\ Ethiopia.
}

Received: September 27, 2019; Published: October 16, 2019

DOI: $10.31080 /$ ASMS.2019.03.0440

\begin{abstract}
Background: Immunization averts an estimated 2 to 3 million deaths every year globally. In Ethiopia only quarter of children are fully immunized; the rest are remained at risk for vaccine-preventable mortality. To increase the immunization, its coverage and predictors has to be identified. This study has measured immunization coverage and identified the predictors.

Objective: To assess the immunization coverage and associated factors among less than five years children Bila town west Wellega zone, Oromia Regional State, Ethiopia

Method: Community based cross sectional study, systematic random sampling technique was used to331 participants select the study subjects. The data was collected by using face to face interview. Data was analyzed manually.

Result: It was found that $64.8 \%$ of the under-five children in this study were fully immunized while the proportion of children who were partially immunized and not immunized was $31.46 \%$ and $3.74 \%$ respectively. Mother's education, age and occupational status were associated factors for immunization of children.
\end{abstract}

Keywords: Immunization Coverage; Less Than Five Years Children; Western Ethiopia

\section{Abbreviations}

FIC: Fully Immunized Child; HSDP: Health Sector Development Plan; IMR: Infant Mortality Rate; EPI: Expanded Program on Immunization; MDGs: Millennium Development Goals; NPP: National Population Policy; U5MR: Under-5 Mortality Rate; WHO: World Health Organization;

\section{Background}

Worldwide about 29,000 children under the age of five die every day, mainly from preventable causes. Every year around 8 million children in developing countries die before they reach their fifth birthday; many during the first year of life [1]. Immunization is a proven tool for controlling and eliminating life-threatening infectious diseases and it is estimated to avert between 2 and 3 million child deaths each year [2]. Routine immunization is considered as the most cost effective Public Health interventions and was first introduced in I Ethiopia in the year 1978. Ethiopia placed sixth among the countries of the world in terms of child death as about 472,000 Ethiopian children die each year before their fifth birthday. Most of these deaths occur from few preventable and curable diseases and conditions [3].
Globally, 130 million children are born annually and 91 million of these are in developing countries. However, 10 million of these children under five years of age die every year. Over 27 million infants do not get full routine immunizations. Every year more than 10 million children in low and middle income countries die before they reach their fifth birthday. Most of them die because they do not have access to effective interventions that combat common and preventable childhood illnesses [8]. Infant and under-five mortality rates in Ethiopia are some of the highest in the world. One of the major causes of this mortality is vaccine preventable diseases [9]. EPI was started in Ethiopia in 1980 with the aim of reducing morbidity and mortality of children and mothers from vaccine preventable diseases. During the inception of EPI the objective was to increase immunization coverage by $10 \%$ annually but this target has not been realized even after two decades because of factors such as poor health infrastructure, low number of trained manpower, high turnover of staff and lack of donor funding. The same factors still affect the program today. The target group when the program started were children under two years of age until it changed to one year in 1986 to be in line with the global immunization target [10] 
According to the Ethiopian Demographic and Health Survey (EDHS) 2005, only $20 \%$ of children 12 - 23 months of age were fully vaccinated and $24 \%$ of children did not receive any vaccination. Accordingly, children are more likely to be vaccinated the first doses of vaccination than the third and the fourth doses in which $60 \%$ of children received Bacillus Calmette- Guirin (BCG) and from these only $35 \%$ of them receive measles vaccine which is the last vaccine dose in EPI program of Ethiopian. This shows that there is a high rate of drop out from vaccination [11]. In Ethiopia, low access to services, inadequate awareness of caregivers, missed opportunities, and high dropout rate are major factors contributing to low EPI coverage. Therefore, the aim of this study is to assess the immunization coverage and associated factors among less than five year children in Bila town According to guidelines developed by the World Health Organization (WHO), children are considered fully vaccinated when they have received a vaccination against tuberculosis Bacillus Calmette Guerin (BCG), three doses each of diphtheria, pertussis and tetanus toxoids (DPT),three doses of polio vaccines, and a measles vaccination by the age of 12 months. Since Ethiopia included Hemophilus influenza type B (HiB) and hepatitis B (Hep B) as of 2007; pentavalent vaccine (DPT plus Hep $B$ and Hib) has replaced the previous DPT vaccine [12]. World Health organization reports indicated by the year 2011 worldwide coverage of three doses of DTP, one dose of measles and three doses of polio vaccine were $83 \%, 84 \%$ and $84 \%$ respectively. However, more than one-fifth of the world's children, especially those in lowincome countries, were still not fully vaccinated at 12 months of age and remained at risk for vaccine-preventable morbidity and mortality [13]. Complete immunization coverage in Kenya by the year 2011 was $76.6 \%$ with $99.5 \%$ BCG and $77.4 \%$ measles coverage. Identified predictors were number of children within the family, place of birth of the child, and opinion on the health immunization services offered [14]. In 2005 Indian complete status immunization was $44 \%$ almost similar with Pakistan and factors identified were mother education, mother religion and child birth order [15]. In Ethiopia, the vaccination policy calls for BCG vaccine given at birth or at first clinical contact, three doses of pentavalent (DPT-Hep B-Hib) vaccine and the newly added pneumococcal conjugate vaccine (PCV) vaccine given at approximately 4, 8, and 12 weeks of age, four doses of oral polio vaccine given approximately at $0-2,4,8$, and 12 weeks of age, and measles vaccine given at or soon after reaching 9 months of age [16]. All these vaccines are recommended to be given within one year of a child age. Ethiopian central statistics agency in its 2011 demographic and health survey found that $24 \%$ of Ethiopian children 12 - 23 months age have received all recommended vaccines; one dose each of BCG and measles, and three doses each of DPT and polio (excluding polio zero vaccine given at birth). The finding of this survey showed improved immunization coverage as compared with similar survey in 2005 which revealed that only $20 \%$ of children $12-23$ at the time. The 2011 survey also reported fifteen percent of children did not receive any of the recommended vaccines. Vaccination coverage is more than double in urban areas than in rural areas of the country (48\% versus 20\%) [17]. In contrast with this national survey other studies; a 2006 survey reported $49.9 \%$ in nationwide, a 2008 survey in Wonago district $41.7 \%$ and in 2011 at Ambo district 36\% of the children were fully vaccinated [18]. Ethiopian demographic and health survey (EDHS) 2011 also calculated coverage for specific vaccines, 66 percent of children received the BCG vaccine, and 56 percent had received the measles vaccine. A relatively high percentage of children received the first DPT dose (64\%). However, only $37 \%$ went on to receive the third dose of DPT. More than eight children of every ten ( $82 \%$ ) received the first dose of polio, but only $44 \%$ received the third dose [Central Statistical Agency [19]. According to guidelines developed by the WHO and shared by Ethiopia, a child is considered fully immunized when he/she has received one dose of BCG, three doses of DPT (since Ethiopia included HiB and HepB since 2007; pentavalent vaccine (DPT + Hep B_Hib) has replaced the previous DPT vaccine), three doses polio vaccines excluding polio zero given at birth and a measles vaccination by the age of 12 months. A child is considered as partially immunized if received any vaccines but missed at least one dose of one BCG, three doses of pentavalent, three doses of oral polio vaccine (OPV) and a measles vaccine. A child is considered as not immunized if he/she does not receive any dose of vaccines [20].

A study conducted in Arba Minch Town and Arba Minch Zuria district showed that children had taken measles $(77.6 \%)$ as compared with $91.0 \%$ of children were vaccinated for BCG. As shown in the figure below corresponding vaccination reduction has been recorded from first to second and third doses of Polio, Pentavalent and PCV vaccines. Even though 93.0\%, 92.9\% and 91.9\% of children had started Pentavalent, PCV and Polio vaccines only $89.8 \%$, $86.3 \%$ and $86.3 \%$ had completed the recommended third doses of each vaccine respectively. Sharing the definitions given by WHO nearly three fourth $(73.2 \%)$ of children, the rest $20.3 \%$ and $6.5 \%$ are partially immunized and not immunized/vaccinated respectively [21].

\section{Method}

Institutional based descriptive cross-sectional study was conducted from January 1, 2017 to January 20, 2019 G.C at Ambo, university which were west shoa zone central Ethiopia. The sample size was calculated using single population proportion formula by assuming population proportion. To calculate the proportion formula, an estimate of $73.2 \%$ is taken from Arba Minch town and Zuria District, Southern Ethiopia, 2013. To get the possible sample at $95 \%$ confidence interval, which is Z-value of 1.96 and marginal error of 5\%, it is calculated as follows:

$$
n=\frac{(z \alpha / 2)^{2 *} p(1-p)}{d^{2}}
$$

Where

$\mathrm{p}=$ Estimated proportion of the under five years old children take fully immunization 
$\mathrm{Z}=$ Level of confidence interval 95\%=1.96

$\mathrm{d}=$ Degree of precession (the margin of sampling error to be used $=0.05$

$\mathrm{q}=1-\mathrm{p}$

$\mathrm{n}=\frac{(1.96)^{2 * 0.732(1-0.732)}}{(0.05)^{2}}=301$

In addition, by considering the non-response rate $10 \%$ final sample size was calculated as; $\mathrm{n}=\mathrm{nf}+10 \% \mathrm{nf}=331 \mathrm{In}$ addition the amount of data collected qualitatively was determined by the saturation of the data collected.

Ethical clearance was obtained from Ambo University research committee written informed consent for participation in the study was obtained from participants just after start of the interview.

\section{Results}

Socio-demographic characteristics of mothers or caregivers

A total of 331mothers or care givers of children less than five years were interviewed with a response rate of $100 \%$. Of the total 331 respondents, 315 (95.2\%) were mothers of the children and 16 (4.8\%) were caregivers. The majority 321 (97\%) of respondents belong to Oromo ethnic group, 268 (81.9\%) of them protestant Christian and 43 (13\%) Muslim in religion.

The median age of the mothers or caregivers was 28 ( \pm 6.1 SD) years, which ranges from 17 to 58 years. From the total respondents, $190(57.4 \%)$ attended primary school, while 33 (9.4\%) completed secondary school and above level and 108 (32.2\%) of them can't read and write. More than half, 186 (56.2\%) of mothers or caregivers and 175 (52.9\%) of fathers were farmers. Socio-demographic characteristics of children from a total of 331 children included in the study, 133 (40.2\%) were females, 198 (59.8\%) were males From the total children who have participated in this study, $323(97.6 \%)$ were vaccinated at least once and $8(2.4 \%)$ were never vaccinated (Table 1).

\begin{tabular}{|l|c|c|}
\hline \multicolumn{1}{|c|}{ Variables } & Frequency & Percentage \\
\hline $\begin{array}{l}\text { Respondent's relation with } \\
\text { child }\end{array}$ & & \\
\hline Mothers & 315 & 95.2 \\
\hline Fathers & 7 & 2.1 \\
\hline Caregivers & 9 & 2.7 \\
\hline Age of the Mother (years) & & \\
\hline$<20$ & 47 & 14.2 \\
\hline $21 \_25$ & 78 & 23.6 \\
\hline $26 \_30$ & 178 & 53.8 \\
\hline$>30$ & 28 & 8.5 \\
\hline Family Type & 279 & 84.3 \\
\hline Nuclear & 52 & 15.7 \\
\hline Joint & & \\
\hline
\end{tabular}

\begin{tabular}{|c|c|c|}
\hline $\begin{array}{l}\text { Monthly family income } \\
\text { (Rs.) }\end{array}$ & & \\
\hline$<300$ & 7 & 2.1 \\
\hline 301_600 & 103 & 31.1 \\
\hline 601_1000 & 88 & 26.6 \\
\hline$>1000$ & 133 & 40.2 \\
\hline \multicolumn{3}{|c|}{ Education status of Mother } \\
\hline No formal education & 56 & 16.9 \\
\hline Elementary school & 186 & 56.2 \\
\hline High school & 60 & 18.1 \\
\hline Diploma and above & 29 & 8.8 \\
\hline \multicolumn{3}{|l|}{ Occupation of mother } \\
\hline House wife & 211 & 63.7 \\
\hline Merchant & 53 & 16.0 \\
\hline Government employed & 31 & 9.4 \\
\hline Others & 26 & 7.9 \\
\hline \multicolumn{3}{|l|}{ Sex of child } \\
\hline Male & 154 & 46.5 \\
\hline Female & 177 & 53.5 \\
\hline \multicolumn{3}{|l|}{$\begin{array}{l}\text { Age(in months) of the } \\
\text { child }\end{array}$} \\
\hline$<12$ & 47 & 14.2 \\
\hline $12-23$ & 72 & 21.8 \\
\hline $24-35$ & 80 & 24.2 \\
\hline $36-47$ & 64 & 19.3 \\
\hline $48-60$ & 68 & 20.5 \\
\hline
\end{tabular}

Table 1: Socio-demographic characteristics of children less than five years in Bila town, west walega zone, Oromia region, western Ethiopia, 2017.

\section{Availability and accessibility of vaccination services}

Availability and accessibility of vaccination services Almost all, $331(100 \%)$ of respondents reported that they have access to health facilities that provide immunization services. Majority of them, $305(92.1 \%)$ reported that they have more access to health center, 305 (92.1\%) have access to services provided at health center and $26(7.9 \%)$ to services provided during outreach. As far as average distance to health facility in travel hours or minutes was concerned, 325 (98.2\%) of respondents have travelled $\leq 15$ minutes and $6(1.7 \%)$ travelled greater than an hour (Table 2).

\section{Immunization coverage with different vaccines}

It was found that $64.8 \%$ of the under-five children in this study were fully immunized while the proportion of children who were partially immunized and not immunized was $31.46 \%$ and $3.74 \%$ respectively. This study found that coverage with BCG vaccine was 94.4\%. The coverage of three doses of DPT, Oral Polio and Hepatitis B vaccine was found to be $76 \%$ whereas coverage for measles vaccine was $77.2 \%$. 


\begin{tabular}{|l|c|c|}
\hline Variable & Frequency & Percentage \\
\hline Presence health facility & & \\
\hline Yes & 331 & 100 \\
\hline No & 0 & 0 \\
\hline Number of health facilities & 1 & \\
\hline Health center & 3 & \\
\hline Private clinic & & \\
\hline Travel time to Nearest Vaccine site & 325 & 98.2 \\
\hline$<15$ minutes & 6 & 1.7 \\
\hline$>0$ ne hour & & \\
\hline Know local Vaccine site schedule & 241 & 72.8 \\
\hline Yes & 90 & 27.2 \\
\hline No & & \\
\hline Ever return without getting vaccine & 293 & 88.5 \\
\hline Yes & 38 & 11.5 \\
\hline No
\end{tabular}

Table 2: Availability and accessibility of vaccination services.

\begin{tabular}{|l|c|c|}
\hline Vaccine & Yes N (\%) & No N (\%) \\
\hline BCG & $252(76.1)$ & $79(13.9)$ \\
\hline Pent3 & $306(92.4)$ & $25(7.6)$ \\
\hline OPV3 & $306(92.4)$ & $25(7.6)$ \\
\hline Measles & $268(81)$ & $63(19)$ \\
\hline Polio & $306(92.4)$ & $25(7.6)$ \\
\hline
\end{tabular}

Table 3: Immunization coverage with different vaccines.

Factors association Immunization Status of the Child

Age, educational status and occupational status of the mothers were associated with the immunization status of the child.

\section{Discussion}

This study assessed the complete immunization coverage and factors associated with it among children less than five years old in Bila town of Oromia Regional State, western Ethiopia. The pentavalent 3 coverage was $92.4 \%$ and $81 \%$ took measles. The OPV vaccine

\begin{tabular}{|c|c|c|c|}
\hline \multirow[t]{2}{*}{ Variable } & \multicolumn{2}{|c|}{ Immunization status } & \multirow[t]{2}{*}{$\mathbf{P}$-value } \\
\hline & Fully immunized N (\%) & Partially or not immunized N (\%) & \\
\hline \multicolumn{4}{|l|}{ Mothers age in years } \\
\hline$<20$ & $27(57.4)$ & $20(42.6)$ & 0.03 \\
\hline $21-25$ & $47(60.3)$ & $31(39.7)$ & \\
\hline $26-30$ & $131(73.6)$ & $47(26.4)$ & \\
\hline$>30$ & $22(78.6)$ & $6(21.4)$ & \\
\hline \multicolumn{4}{|c|}{ Educational status of mothers } \\
\hline no formal education & $26(46.4)$ & $30(53.6)$ & 0.02 \\
\hline Elementary school & $134(72.0)$ & $52(28.0)$ & \\
\hline High school & $43(71.7)$ & $17(28.3)$ & \\
\hline Diploma and above & $27(93.1)$ & $2(6.9)$ & \\
\hline \multicolumn{4}{|l|}{ Occupational status } \\
\hline House wife & $193(91.5)$ & $18(8.5)$ & \\
\hline Merchant & $31(58.5)$ & $22(41.5)$ & 0.01 \\
\hline Government employed & $28(90.3)$ & $3(9.7)$ & \\
\hline Others & $17(65.4)$ & $9(34.6)$ & \\
\hline
\end{tabular}

Table 4: Factors association Immunization Status of the Child.

coverage was higher than the coverage of the pentavalent vaccine. The penta3 coverage was higher than the measles coverage. It is logical acceptable and the long time gap between the two vaccines, in which the mother may not return back the measles vaccine. The higher coverage of measles and OPV vaccination was assumed to be due to the frequent national campaign that focused on the two vaccines.

Compared the immunization coverage of Bila town with the EDHS 2016, the proportion of children fully vaccinated in the present study was higher by $39 \%$, but it was similar by proportions of unvaccinated children [10]. Beside this, the current findings is higher than the 2006 immunization coverage survey in the country which estimated fully vaccinated by card is only at $20 \%$ [18]. But it is lower than the immunization coverage reported in the 2008 health and health related indicators [19] and 2010 woreda health office report. This difference is may be due to the over reporting of health and health related indicators data from some areas.

From the total interviewed households, 291 (87.9\%) mothers showed the vaccination card of their children. The coverage by card only was also less than that of health and health related indicators. 
The proportion of fully vaccinated children in this study was about 8\% higher than the EDHS 2016 and 2015 EPI survey coverage $[10,18,19]$. This difference is because of the result from such country level study includes area of low immunization coverage.

\section{Declarations}

Ethics approval and consent to participate

The study proposal was initially approved by the ethical review board of Ambo University. A formal letter of permission was obtained from the college and submitted to department. The information about the study was given to the participants. Verbal and then written informed consent was sought from each participant who agreed to participate in the study and full filled the inclusions criteria. Only anonymous data collected in private rooms.

\section{Availability of data and materials}

This study is a part of institutional based a descriptive cross sectional study on Immunization coverage and associated factors among under-five year old children in. The dataset pertaining to this study will be shared upon reasonable request.

\section{Conflict of Interests}

The authors declare that they have no competing interests.

\section{Authors' Contributions}

TakeleT has involved in advice all part of activities. All of us read and approved the final manuscript. Teferra L. has involved edited the all part of manuscript Dawit E. has involved in the conception, design, analysis, data interpretation and report writing.

\section{Acknowledgements}

We would like to acknowledge Ambo University College of Medicine and Health Science for funding this study, In addition, we would like to thank data collectors and study participants.

\section{Bibliography}

1. UNICEF: Millennium Development Goal report. UNICEF (2005).

2. World health organization: Immunization (2012).

3. Federal Ministry of Health (MOH): Ethiopia: Health and health related indicator of Ethiopia. Addis Ababa: Planning and Programming Department, FMO (2006).

4. World Health Organization. "Immunization against diseases of public health importance". Geneva. (2005): 288.

5. World Health Organization. "Immunization in practice: Modules for health staff update". Geneva. (2004).

6. Gore P., et al "Predictors of childhood immunization completion in a rural population". Social Science and Medicine 48 (1999):1011-1027.
7. Rahman M., et al 'Mothers' knowledge about vaccine preventable diseases and immunization coverage in a population with high rate of illiteracy". Trop Pediatrics 41.6 (1995): 376-378.

8. Kalaivani K., et al "Editorial". News Lett Nat Inst Health Fam Welfare 8 (2006):1-2.

9. National Population policy, Ministry of Health and Family Welfare. Government of Ethiopia; New Delhi: (2000).

10. WHO: EPI coverage fact sheet (2013).

11. Centers for Disease Control and Prevention: Ten great public health achievements United States, 1900-1999.

12. Belachw E and Wakgari D. "Factors associated with complete immunization coverage in children aged 12-23 months in Ambo District, Central Ethiopia". BMC Public Health (2012).

13. WHO: Global routine vaccination coverage The Weekly Epidemiological Record on 2 (2011).

14. Maina L., et al "Immunization coverage and its determinants among fewer than fiveyear children in a peri-urban area of Kenya". Pan African Medical Journal (2013).

15. NazishS., et al "Assessment of EPI (Expanded program of immunization) vaccine coverage in a peri-urban area of Karachi". Journal of Pakistan Medical Association 57.8 (2007): 391-395.

16. Federal Democratic Republic of Ethiopia Ministry of Health: Health Sector Development Program IV 2010/11 - 2014/15. Addis Ababa, Ethiopia: FMOH (2010).

17. Central Statistical Agency [Ethiopia] and ICF International: Ethiopia Demographic and Health Survey 2011, Addis Ababa, Ethiopia and Calverton, Maryland, USA: Central Statistical Agency and ICF International (2012).

18. Teklay K., et al "National EPI coverage survey report in Ethiopia (2006).

19. Ethiopia] and ICF International: Ethiopia Demographic and Health Survey (2011).

20. WHO: "WHO Handbook for Guideline Development. Geneva: World Health Organization (2012).

21. WorkuAnimaw., et al "Expanded program of immunization coverageand associated factors among children age12-23 months in Arba Minch town and Zuria District, Southern Ethiopia (2013).

\section{Volume 3 Issue 11 November 2019 (C) All rights are reserved by Takele Tiki., et al.}

